\title{
Respiratory and Gastrointestinal Involvement in Birth Asphyxia
}

\author{
Rohit Vohra ${ }^{1 *}$, Vivek Singh ${ }^{2}$, Minakshi Bansal ${ }^{3}$ and Divyank Pathak ${ }^{4}$ \\ ${ }^{1}$ Senior resident, Sir Ganga Ram Hospital, India \\ ${ }^{2} J u n i o r$ Resident, Pravara Institute of Medical Sciences, India \\ ${ }^{3}$ Fellow pediatrichematology, Sir Ganga Ram Hospital, India \\ ${ }^{4}$ Resident, Pravara Institute of Medical Sciences, India
}

Submission: December 01, 2017; Published: May 14, 2018

*Corresponding author: Dr Rohit Vohra, Senior resident, Sir Ganga Ram Hospital, 22/2A Tilaknagar, New Delhi-110018, India, Tel: 9717995787; Email: drrohitvohra87@gmail.com

\begin{abstract}
Background: The healthy fetus or newborn is equipped with a range of adaptive, strategies to reduce overall oxygen consumption and protect vital organs such as the heart and brain during asphyxia. Acute injury occurs when the severity of asphyxia exceeds the capacity of the system to maintain cellular metabolism within vulnerable regions. Impairment in oxygen delivery damage all organ system including pulmonary and gastrointestinal tract. The pulmonary effects of asphyxia include increased pulmonary vascular resistance, pulmonary hemorrhage, pulmonary edema secondary to cardiac failure, and possibly failure of surfactant production with secondary hyaline membrane disease (acute respiratory distress syndrome).Gastrointestinal damage might include injury to the bowel wall, which can be mucosal or full thickness and even involve perforation
\end{abstract}

Material and methods: This is a prospective observational hospital based study carried out on 152 asphyxiated neonates admitted in NICU of Rural Medical College of Pravara Institute of Medical Sciences, Loni, Ahmednagar, Maharashtra from September 2013 to August 2015.

Results: Respiratory system involvement was seen in 68 (45\%) neonates.112 neonates (73.6\%) had no/ mild respiratory distress (Downe's score $0-3$ ) while $24 \%$ and $35 \%$ of children who had asphyxia had moderate and severe respiratory distress respectively. A total of 24 neonates had features suggestive of NEC out of which 17 had grade I, Grade II NEC was seen 6 neonates while only one had grade III NEC.

Conclusion: Respiratory and GIT involvement in birth asphyxia is a common and are important causes of morbidity and as well as mortality.

Keywords: Birth asphyxia; Respiratory distress; NEC; Mechanical ventilation

\section{Introduction}

Asphyxia at a pathophysiological level, is the simultaneous combination of both hypoxia and hypoperfusion, which impairs tissue gas exchange, leading to tissue acidosis. During normal labor, transient hypoxemia occurs with uterine contractions, but the healthy fetus tolerates this well.

The healthy fetus or newborn is equipped with a range of adaptive, strategies to reduce overall oxygen consumption and protect vital organs such as the heart and brain during asphyxia. Acute injury occurs when the severity of asphyxia exceeds the capacity of the system to maintain cellular metabolism within vulnerable regions.

The pulmonary effects of asphyxia include increased pulmonary vascular resistance, pulmonary hemorrhage, pulmonary edema secondary to cardiac failure, and possibly failure of surfactant production with secondary hyaline membrane disease (acute respiratory distress syndrome). Meconium aspiration if present may add to the problems [1]. The respiratory system may require support for respiratory distress syndrome or pulmonary hypertension. The goal in management of the respiratory system is moderation in oxygen and carbon dioxide levels. Hypoxia and hyperoxia can lead to further neuronal injury. Hypercarbia can lead to cerebral vasodilatation and hemorrhage, whereas hypocarbia can lead to decreased cerebral blood flow [2].

In the severely depressed infant, the necessity for very early artificial ventilation with oxygen is undisputed. However, there are differences of opinion about the advisability of a brief attempt at bag and mask ventilation prior to endotracheal intubation. There is a general agreement that respiratory stimulants are not helpful in resuscitating the severely asphyxiated infant [3].

During the initial period of asphyxia, rapid but ineffective breathing occurs within $30 \mathrm{sec}$ of the onset of hypoxia. These rapid respirations last for about $30 \mathrm{sec}$ and then stop. If asphyxia continues the heart rate falls and muscle tone is lost. 
Cyanosis and decreased capillary blood flow occurs secondary to vasoconstriction. This period of time is termed primary apnea. Resuscitation efforts begun during this time are usually successful and often require only supplemental oxygen and tactile stimulation to reestablish respiration.

It resuscitation does not take place, rhythmic gasping then begins and continues for 4-5min, slowly it becomes weaker and weaker until the infant takes a final gasp and enters the period called secondary or terminal apnea. Resuscitation will require artificial ventilation using positive pressure bag and mask and oxygen to establish spontaneous and effective respiration [4].

Birth asphyxia has been documented as the primary cause of respiratory distress in newborns, especially the term neonates, which resolves over a period of time with supplementary oxygen. A few having persistent respiratory distress need ventilatory support.

Gastrointestinal damage might include injury to the bowel wall, which can be mucosal or full thickness and even involve perforation. The extent of the damage influences the nutritional management, in particular when to begin feedings once recovery occur [2]. The shunting of blood away from the intestine in a fashion similar to the diving reflex in aquatic mammals has been postulated as a potential mechanism for producing the initial gut ischemia. This reflex occurs most commonly in response to asphyxia and it forms the basis of gastrointestinal involvement in birth asphyxia.

The asphyxiated infant is at risk for bowel ischemia and necrotizing enterocolitis (NEC) [5]. Probably the most serious gastrointestinal disorder occurring in neonates is necrotizing enterocolitis.

Clinical presentations vary widely. Abdominal distention usually is one of the earliest and most consistent clinical signs. Other symptoms include bloody stools, apnea, bradycardia, lethargy, shock and retention of gastric contents due to poor gastric emptying. Thrombocytopenia, neutropenia and metabolic acidosis may develop during bowel ischemia. Feeding intolerance and subtle alterations of intestinal motor activity and gastrointestinal peptides have been reported in association with perinatal asphyxia [6].

\section{Material and Methods}

\section{Study design}

Prospective Observational hospital based Study.

\section{Data collection}

All asphyxiated newborns delivered at Pravara Institute of Medical Sciences, Loni from September 2013 to August 2015 who had features of birth asphyxia with Apgar score of $\leq 7$ at $5 \mathrm{~min}$ or/ and Umbilical cord arterial $\mathrm{pH}$ of $<7.2$ at birth or/and required more than 1 minute of positive pressure ventilation before sustained respiration or the need for mechanical ventilation at birth were included in the study.
Neonates born before 37 weeks of gestation, or born outside Pravara Institute of Medical Sciences, Loni or with congenital anomalies or with early onset sepsis were excluded from study.

Approval from the institutional ethics committee and written consent was taken from all parents before inclusion of their child in the study.

A detailed history was taken and examination performed at the time of admission to NICU. The neonatal clinical course was followed up to 14 days of birth .The data so obtained was be recorded. Natal history was taken to find out the mode of delivery and indications for interventions, if any. Complications during and prior to labour were noted.

All births were attended and resuscitated by the pediatricians. For resuscitation Neonatal Resuscitation Protocol of American Academy of Pediatrics 2010 was followed [6]. Postnatal history was obtained regarding birth asphyxia and for details of resuscitation measures done at birth, APGAR score at $1 \mathrm{~min}$. and $5 \mathrm{~min}$. was assessed.

Gestational age in completed weeks was assessed on basis of mother's last menstrual period and confirmed where ever necessary by routine early antenatal ultra sonography (USG) examination. In cases where ever last menstrual period (LMP) was not available and antenatal USG was not done, then gestational age was assessed by Modified Ballard Scoring system [7].

All biochemical samples were taken on admission. Special investigation like echocardiography was done at Department of Radiology at Pravara Institute of Medical Sciences, Loni.

Daily follow-up of the patient was done and overall progress was monitored till the discharge from NICU or death of the baby

\section{Respiratory System}

- Assessment of respiratory distress was done by Downe's score.

- A score of $<4$ was defined as no/ mild respiratory distress,

- $\quad$ 4-7 was defined as moderate respiratory distress

- $\quad$ And $>7$ was defined as severe respiratory distress.

Respiratory status monitering was done in all neonates included in the study by modified downe's score on hourly basis till 48 hrs after birth. Any child with moderate respiratory distress was started on 02 inhalation via nasal prongs to maintain a SPO2 more than $92 \%$ and children having severe respiratory distress and/ apnea was started on mechanical ventilation.

Chest X-ray was performed in all infants needing oxygen supplementation. Abnormal chest $\mathrm{X}$ ray was defined as any of the following features pulmonary infiltrates, patchy hyperinflation and atelectasis, air leaks, loss of lung volume, ground glass appearance or white out lungs (Figure 1). 


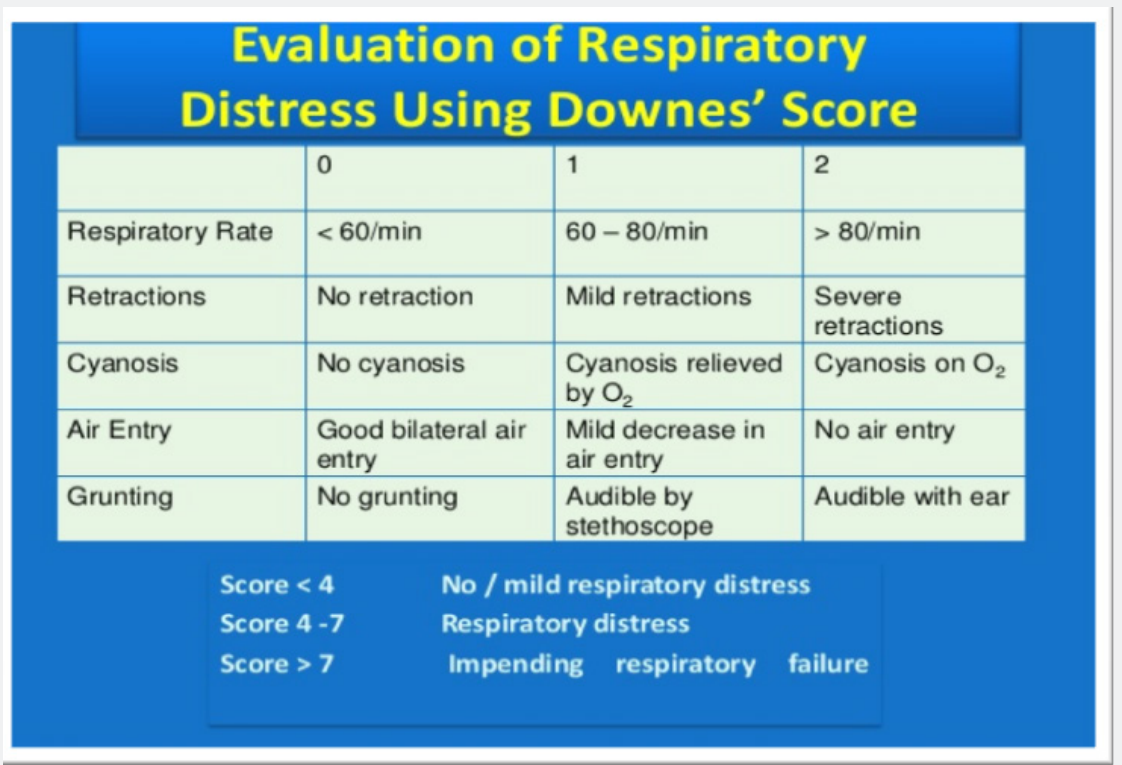

Figure 1: Downe's Scoring System.

\section{Gastrointestinal evaluation}

Enteral feeding was started after 24 hours after birth in all cases via naso- gastic tube after ruling out active GI bleed. Feeds were started at a rate of $10-20 \mathrm{ml} / \mathrm{kg} /$ day and advanced at a rate of $20 \mathrm{ml} / \mathrm{kg} /$ day upto a maximum of $120 \mathrm{ml} / \mathrm{kg} /$ day. All infants were started on expressed breast milk. All infants were monitered for presence of GI bleed, abdominal distension, and altered GI aspirate, or any features suggestive of NEC. Modified Bell's criteria were used for diagnosis of necrotizing enterocolitis. If we were unable to provide enteral feeds to the child even after 72 hours after birth TPN was started (Figure 2).

\begin{tabular}{|c|c|c|c|}
\hline Stage & Gastrointestinal signs & Systemic signs & Radiological findings \\
\hline Stage IA & Increasing gastric aspirates, mild abdominal & Temperature instability, & Normal to mild ileus \\
\hline Suspected NEC & distension, fecal occult blood & apnea, bradycardia, lethargy & \\
\hline Stage IB & As above plus fresh blood per-rectum & As above & As above \\
\hline \multicolumn{4}{|l|}{ Suspected NEC } \\
\hline Stage IIA & As above plus absent bowel sounds & As above & Intestinal dilatation, ileus, \\
\hline Confirmed NEC & on auscultation & & pneumatosis intestinalis \\
\hline Stage IIB & As above plus abdominal tenderness \pm & As above plus mild metabolic & As above plus portal vein \\
\hline Confirmed NEC & abdominal mass & acidosis and thrombocytopenia & gas and ascites \\
\hline Stage IIIA & As above plus marked distension and & As above plus hypotension & As above \\
\hline Advanced NEC & tenderness + generalised peritonitis & and severe apnea & \\
\hline Stage IIIB & As above & As above & As above plus \\
\hline Advanced NEC & & & pneumoperitoneum \\
\hline
\end{tabular}

Figure 2: Modified Bell's criteria for NEC.

\section{Statistical analysis}

Values have been expressed as Mean \pm SD. The data were compiled and analyzed using descriptive statistics using student t-test. P value $<0.05$ was considered to be significant.

\section{Results}

Total 152 asphyxiated babies were included in the study. In this study out of 152 neonates, 84 were males and 62 females. $55.17 \%$ of our patients were delivered by vaginal delivery, while $38 \%$ of them were delivered by cesarean section.

112 neonates $(73.6 \%)$ had no/ mild respiratory distress (Downe's score $0-3$ ) while $24 \%$ and $35 \%$ of children who had asphyxia had moderate and severe respiratory distress respectively (Table 1) (Graph 1).

Table 1: Downe's Score in Respiratory Distress.

\begin{tabular}{|c|c|c|}
\hline Downe's Score & No. of cases & Percentage \\
\hline $\begin{array}{c}0-3 \text { (No/Mild } \\
\text { distress) }\end{array}$ & 112 & $73.6 \%$ \\
\hline $\begin{array}{c}\text { 4-6 (Moderate } \\
\text { distress) }\end{array}$ & 16 & $10.5 \%$ \\
\hline $7-10$ (Severe distress) & 24 & $15.7 \%$ \\
\hline Total & 152 & $100 \%$ \\
\hline
\end{tabular}




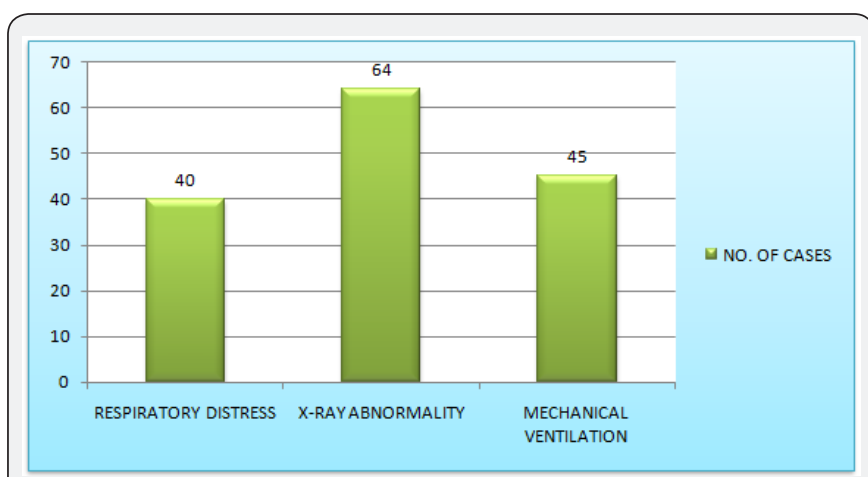

Graph 1: Bar Diagram: Respiratory System Involvement in Cases of Perinatal Asphyxia.

X ray abnormalities were seen in $64(42 \%)$ of neonates. 45 $(29.6 \%)$ of neonates required mechanical ventilator support (Table 2).

Table 2: Gastrointestinal System Involvement in Form of NEC in Cases of Perinatal Asphyxia.

\begin{tabular}{|c|c|c|}
\hline NEC & No. of cases & Percentage \\
\hline Grade IA & 05 & $3.3 \%$ \\
\hline Grade IB & 12 & $7.8 \%$ \\
\hline Grade IIA & 05 & $3.3 \%$ \\
\hline Grade IIB & 01 & $0.6 \%$ \\
\hline Grade IIIA & 01 & $0.6 \%$ \\
\hline Grade IIIB & - & - \\
\hline Total & 24 & $15.6 \%$ \\
\hline
\end{tabular}

A total of 24 neonates had features suggestive of NEC out of which 17 had grade I, Grade II NEC was seen 6 neonates while only one had grade III NEC.

\section{Discussion}

\section{Respiratory involvement}

In present study is having the involvement of the pulmonary system in 68 (45\%) neonates (Table 3).

Table 3: Respiratory involvement in various studies.

\begin{tabular}{|c|c|}
\hline Study & Respiratory Involvement \\
\hline Present study & $45 \%$ \\
\hline Martin Ancel et al. [7] & $26 \%$ \\
\hline Perlman [8] & $25 \%$ \\
\hline Shah [9] & $86 \%$ \\
\hline
\end{tabular}

\section{Need for mechanical ventilation}

Mechanical ventilation (MV) was needed by 30\% neonates in the present study. Other studies have found variable results (Table 4).
Table 4: Neonates requiring MV in various studies.

\begin{tabular}{|c|c|}
\hline Study & Mechanical Ventilation \\
\hline Present study & $30 \%$ \\
\hline Finer [10] & $35 \%$ \\
\hline Martin Ancel et al. [7] & $19 \%$ \\
\hline Shah [9] & $86 \%$ \\
\hline
\end{tabular}

\section{Mortality with respiratory involvement}

In present study, mortality rate of $50 \%$ infants was noted among those with pulmonary dysfunction. In the study by Martin Ancel et al. [7] 6\% neonates died due to respiratory involvement. Shankaran et al. [7] had mortality rate of $7 \%$ with pulmonary involvement.

In present study gastrointestinal involvement was seen in $16 \%$ of neonates whereas Martín-Ancel et al. [7] reported GI involvement in $29 \%$ of neonates. Mohammed et al. [11] noted GI involvement in $5.4 \%$ of neonates.

\section{Mortality with gastrointestinal system involvement}

In present study, 29\% neonates died with GIT involvement. In the study by Mohammed et al. [11] death was seen in $50 \%$ of those with GI involvement.

\section{Conclusion}

Multiorgan dysfunction, though a common feature of perinatal asphyxia, is often overlooked. The focus, most of the time, has been on the brain involvement and HIE following perinatal asphyxia. The body system gives priority to preserving the brain function, at the expense of other systems. Most research too has principally focused on the effect of hypoxia- ischemia on the brain while less attention has been paid to the effect on other systems.

\section{Ethical Approval}

Ethical Approval was taken from the institute ethics committee. Authors are required to make a disclose statement in the manuscript. Any financial (funding, stocks, the authors declare no conflicts of interest).

\section{References}

1. Arora S, Evan YS (2004) Manual of neonatal care. In: Cloherty JP, Eric C, Eichenwald, Stark AR (Eds.), ( $5^{\text {th }}$ edn), Lippincott Williams \& Wilkins, USA, pp.536-555.

2. Leuthner SR, Das UG (2004) Low Apgar scores and the definition of birth asphyxia. Pediatr Clin N Am 51(3): 737-745.

3. Behrman RE, James LS, Klaus M, Nelson N, Oliver T (1969) Treatment of the asphyxiated newborn infant. Current opinions and practices as expressed by a panel. J Pediatr 74(6): 981-986.

4. Rajakumar PS, Bhat BV, Sridhar MG, Balachander J, Konar BC, et al. (2008) Cardiac Enzyme Levels in Myocardial Dysfunction in Newborns with Perinatal Asphyxia. Indian J Pediatr 75(12): 1223-1225.

5. Arora S, Evan YS (2004) Manual of neonatal care. In: Cloherty JP, Eichenwald EC, Stark AR (Eds.), ( $5^{\text {th }}$ edn), Lippincott Williams \& Wilkins, pp. 536-555. 
6. Turner-Gomes So, Izukawa T, Rowe RD (1989) Persistence of atrioventricular valve regurgitation and electrocardiographic abnormalities following transient myocardial ischemia of newborn. Pediatr Cardiol 10(4): 191-194.

7. Martín-Ancel A, García-Alix A, Gayá F, Cabañas F, Burgueros M, et al. (1995) Multiple organ involvement in perinatal asphyxia. J Pediatr 127(5): 786-793.

8. Perlman JM, Tack ED, Martin T, Shackelford G, Amon E (1989) Acute systemic organ injury in term infants after asphyxia. Am J Dis Child 143(5): 617-620.

9. Shah P, Riphagen S, Beyene J, Perlman M (2004) Multiorgan dysfunction in infants with post asphyxial hypoxic ischaemic encephalopathy. Arch Dis Child Fetal Neonatal 89(2): F152-F155.

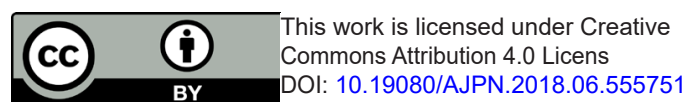

10. Finer NN, Richards RT, Peters KL (1981) Hypoxic ischaemic encephalopathy in term neonates. Perinatal factors and outcome. J Pediatr 98(1): 112-117.

11. Shankaran S, Woldt E, Koepke T, Bedard MP, Nandyal R (1991) Acute neonatal morbidity and long-term central nervous system sequelae of perinatal asphyxia in term infants. Early Hum Dev 25(2): 135-148.

12. Mohammed LH, Mohammed NR, Al-Hussieny NA, Rezq SH (2011) Early predictions of hypoxic-ischemic encephalopathy by umbilical cord nucleated red blood cells and lactate. Med J Cairo Univ 79: 625-631.

\section{Your next submission with Juniper Publishers} will reach you the below assets

- Quality Editorial service

- Swift Peer Review

- Reprints availability

- E-prints Service

- Manuscript Podcast for convenient understanding

- Global attainment for your research

- Manuscript accessibility in different formats

( Pdf, E-pub, Full Text, Audio)

- Unceasing customer service

Track the below URL for one-step submission https://juniperpublishers.com/online-submission.php 